\title{
ANÁLISE DAS MANIFESTAÇÕES PATOLÓGICAS EM UMA EDIFICAÇÃO DO SETOR PÚBLICO
}

\author{
S. MADEIRA, DEISE \\ Eng. ${ }^{a}$ Civil, Aluna de Mestrado \\ Universidade Federal de Itajubá \\ Minas Gerais; Brasil \\ deise.madeira@gmail.com
}

\author{
A. S. OLIVEIRA, CARLOS \\ Professor, Pesquisador \\ Instituição \\ Minas Gerais; Brasil \\ drcarlosaugustooliveira@gmail.com
}

\section{RESUMO}

O presente estudo buscou avaliar o surgimento de manifestações patológicas em uma edificação relativamente nova do setor público localizada em uma cidade do interior de Minas Gerais. No local funciona uma oficina para manutenção de veículos pertencentes ao Poder Público da região que se encontra em pleno funcionamento. Com base no levantamento bibliográfico realizado, inspeção visual, anamnese e registros fotográficos foram analisadas as manifestações patológicas presentes na edificação. A grande maioria das manifestações patológicas detectadas está relacionada ao surgimento de fissuras, trincas e rachaduras, sendo essa última, a que apresenta maior incidência, devido ao atual grau em que as aberturas se encontram. A forma de apresentação de parte das trincas e rachaduras em um ângulo aproximado de $45^{\circ}$ apontam para a existência de um recalque diferencial na fundação da edificação. A circulação de veículos pesados no local associado ao fato de a fundação da edificação ter sido apoiada sob um solo de aterro inerte possivelmente foram fatores que mais contribuíram para a intensificação das manifestações patológicas observadas. Palavras-chave: Manifestações Patológicas. Edificação Pública. Recalque. Itabira.

\section{ABSTRACT}

This study aimed to evaluate the appearance of pathological manifestations in a relatively new public sector building located in a city in the interior of Minas Gerais. On site is a workshop for maintenance of cars belonging to the public authorities of the region and is fully operational. Based on the bibliographic survey, visual inspection, anamnesis and photographic records were analyzed the pathological manifestations present in the building. The vast majority of pathological manifestations detected are related to the appearance of fissures and cracks, the latter having the highest incidence, due to the current degree in which the openings are. The presentation of part of the cracks and cracks at an approximate angle of $45^{\circ}$ points to the existence of a differential repression in the foundation of the building. The circulation of heavy vehicles on site associated with the fact that the foundation of the building was supported under an inert landfill soil were possibly factors that most contributed to the intensification of the observed pathological manifestations.

Keywords: Pathological Manifestations. Public building. Repression. Itabira.

\section{INTRODUÇÃO}

Patologia das Construções trata-se da ciência que possibilita compreender o comportamento das estruturas. Segundo Souza e Ripper (1998), este novo ramo da Engenharia avalia não só a causa da manifestação patológica, como os mecanismos de ocorrência e formas como se apresentam. A relação da ocorrência de manifestações patológicas com a qualidade de vida dos usuários deve estar sempre em análise por seu caráter inversamente proporcional, ou seja, quanto maior a incidência de patologias, mais difícil se torna a garantia de condições de conforto e qualidade na edificação.

De acordo com os critérios estabelecidos pela norma NBR 15575 (ABNT, 2013), é necessário avaliar se os danos causados promovem desconforto apenas a níveis estéticos ou se comprometem a funcionalidade e desempenho estrutural da edificação. Manifestações patológicas podem ser ocasionadas por fatores capazes de promover interferências desde a etapa de concepção do projeto, até as fases de execução e uso e ocupação do local (LAPA, 2008).

As condições para alcance e manutenção do desempenho da estrutura são descritas através das normas NBR 6118 (ABNT, 2014) e NBR 15575 (ABNT, 2013), a partir de especificações relacionadas ao uso, desempenho de materiais, indicação de ensaios a serem realizados ainda na fase de projeto e demais critérios para que a Vida Útil de Projeto 
(VUP) seja alcançada.Fatores como a evolução da tecnologia dos materiais e das técnicas, normalização insuficiente, ausência de cadastramento das patologias e a conjuntura socioeconômica com obras conduzidas rapidamente, deixando muitas vezes a desejar em relação ao controle de qualidade, denotam a importância do estudo de patologias (TAGUCHI, 2010).

Obras públicas são frequentemente citadas pela sociedade como construções de baixa qualidade. Em muitas oportunidades, o que se vê são edificações realizadas com os índices "custo" e "tempo" como fatores preponderantes, deixando a desejar em questões como o controle da qualidade dos materiais e da execução dos serviços prestados.

A Política Nacional de Habitação Urbana representa um dos maiores investimentos financeiros por parte da União, tendo sido construídas no período compreendido entre os anos de 2012 e 2015 aproximadamente 700 mil moradias (TCU, 2016). Apesar do investimento, o Programa Minha Casa Minha Vida (MCMV), lançado em 2009 pelo Governo Federal, pode ser citado como um exemplo de edificações públicas que apresentam alto índice de falhas em seu desempenho. De acordo com o TCU (2016), aproximadamente 56,4\% da amostra definida de unidades pertencentes ao Programa MCMV apresentaram falhas construtivas, como trincas, infiltrações e vazamentos, embora o nível de satisfação dos usuários não tenha sido comprometido.

O relatório elaborado pelo TCU (2016) indica que, embora tenha sido percebido um número considerável de incompatibilidades, vícios construtivos sistêmicos notados nas habitações entregues à população usuária do Programa MCMV não comprometeram as condições de desempenho no que diz respeito aos conceitos de habitabilidade e salubridade. Já o critério de desempenho atua como agente motivador das auditorias realizadas pelo TCU, uma vez que o mesmo não tem sido atendido.

Portanto, percebe-se que diversas obras financiadas e/ou executadas pelo setor público nacional apresentam algum problema construtivo. Isso faz com que tais obras, importantes para o desenvolvimento do Brasil, passem por um processo de deterioração, cuja evolução ao longo do tempo poderá acarretar na perda de seu desempenho e funcionalidade.

Nesse cenário, o presente trabalho tem como objetivo geral identificar e avaliar as principais ocorrências de manifestações patológicas em uma edificação do setor público localizada na cidade de Itabira-MG. O estudo em questão teve como um dos principais agentes motivadores a preocupação relatada por trabalhadores que utilizam frequentemente o ambiente com relação à segurança diante das manifestações patológicas existentes. Dessa forma, o trabalho justifica-se por buscar informações com embasamento técnico que poderão subsidiar a equipe técnica do órgão público em futuras decisões relacionadas à estabilidade da edificação.

\section{DESENVOLVIMENTO}

A ocorrência de manifestações patológicas poderá estar associada a fatores que surgem desde as etapas iniciais a partir da elaboração do projeto, controle e fiscalização da obra, até mesmo a questões como a forma em que a estrutura analisada está sendo utilizada. Além disso, o comportamento próprio de estruturas de concreto deve ser explorado.

Lapa (2008) explana em seu trabalho a importância de se considerar a natureza não inerte do concreto, estando o mesmo sujeito a alterações de seus elementos constituintes a partir da interação com o meio.

\subsection{Patologias das Construções}

O termo Patologia deriva-se do grego "pathos - doença" e "logia - ciência", dessa forma, a Patologia na área das Construções é a ciência que busca definir, a partir dos sinais apresentados, as causas que levaram uma determinada estrutura à manifestação de patologias e alteração das funções de seu desempenho. Patologia das Construções "é a parte da Engenharia que estuda os sintomas, os mecanismos, as causas e as origens dos defeitos das construções civis, ou seja, é o estudo das partes que compõem o diagnóstico do problema" (HELENE, 1992).

Lapa (2008) relata a possibilidade das enfermidades serem congênitas, ou seja, existentes a partir do momento da concepção da estrutura ou adquiridas ao longo do tempo, a partir do contato e ação direta de agentes externos ou fenômenos físicos, o que inclui também fatores como o uso e ocupação da estrutura. 
As edificações estarão sujeitas ao surgimento de falhas das mais diversas naturezas tão logo for iniciada a construção, que poderão ser ocasionadas por fatores que vão desde a qualidade do material empregado e da mão de obra contratada, a até mesmo atos de negligência e irresponsabilidade técnica (SOUZA E RIPPER, 1998). Taguchi (2010) destaca a importância da realização de estudos relacionados à manifestação de patologias no setor da Construção Civil, possibilitando a definição de uma metodologia construtiva e, ao mesmo tempo, a otimização do processo.

\subsubsection{Tipos de manifestações patológicas}

No ramo da Engenharia Civil o termo "manifestação patológica" está associado às intercorrências percebidas na edificação capazes de promover alterações em sua funcionalidade. O estudo destas manifestações compreende a busca por sua origem a partir dos modos de ocorrência e sintomas associados.

No contexto da Construção Civil, é comum o surgimento de manifestações patológicas na estrutura, alvenaria, esquadrias, forros, pintura, revestimentos cerâmicos, instalações elétricas, esquadrias e cobertura, sendo as principais o surgimento de fissuras, corrosão da armadura de aço, manchas, eflorescências e a deterioração do concreto em si.

A Figura 1 representa os dados divulgados em relatório pelo TCU (2016), em que o resultado da perícia realizada a fim de avaliar os índices de manifestações patológicas nas edificações do Programa MCMV é apresentado:

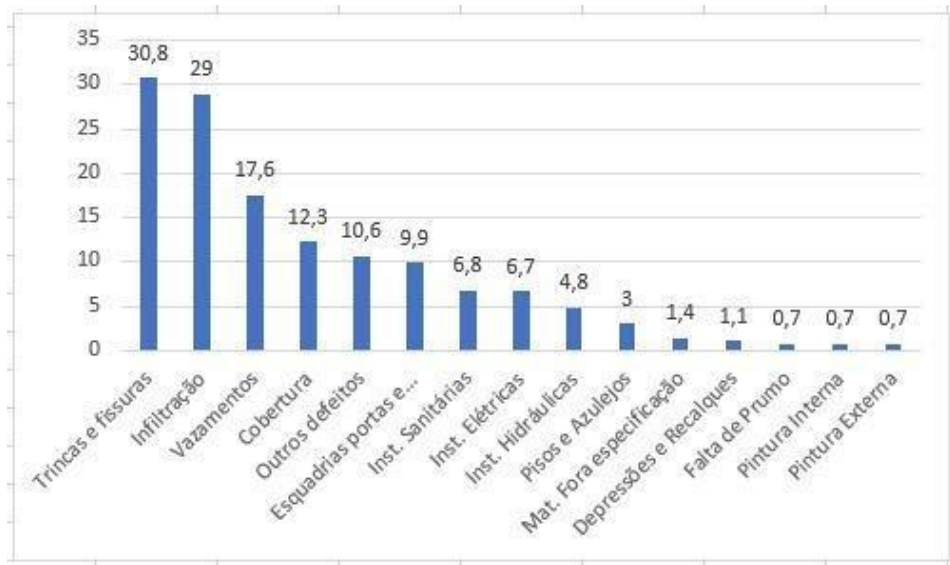

Figura 1: Índice de manifestações patológicas do Programa MCMV (TCU, 2016).

Dentre àquelas mais frequentes, o surgimento de trincas e fissuras nas construções é bastante comum e visível a olho nu já em seus primeiros estágios. Segundo Thomaz (1989), o surgimento de fissuras fornece indícios aos usuários de que algo mais sério está acontecendo com a estrutura, alertando para que a causa desta manifestação patológica seja determinada o quanto antes, para que o desempenho das estruturas não seja comprometido.

Embora este tipo de manifestação patológica seja frequente, o que muitas vezes faz com que pareçam relativamente inofensivas, a forma e velocidade de ocorrência devem ser avaliadas para que os riscos de evolução do problema sejam controlados.

\subsubsection{Fissuras, Trincas e Rachaduras}

Manifestações patológicas do tipo fissuras, trincas e rachaduras têm como principais causas os mecanismos de variação térmica, retração ou expansão dos constituintes, sobrecarga, recalque diferencial de fundação, movimentações higroscópicas e reações químicas (THOMAZ, 1989).

Atualmente, uma série de designações diferentes pode ser utilizada para nomear a ocorrência destes tipos de manifestações patológicas, sendo cada consultor responsável por determinar qual o termo mais adequado para a situação. Contudo, um método de classificação é proposto por Thomaz (1989), levando-se em consideração a espessura da abertura, conforme demonstrado no Quadro 1, sendo estabelecidos os termos fissura, trinca, rachadura, fenda e brecha: 
Tabela 1 - Classificação das anomalias baseadas na abertura apresentada

\begin{tabular}{c|c}
\hline Anomalias & Abertura $(\mathrm{mm})$ \\
\hline Fissura & Até 0,5 \\
\hline Trinca & De 0,5 a 1,5 \\
\hline Rachadura & De 1,5 a 5,0 \\
\hline Fenda & De 5,0 a 10,0 \\
\hline Brecha & Acima de 10,0 \\
\hline \multicolumn{2}{|c}{ Fonte: Oliveira, 2012 }
\end{tabular}

Outro método de classificação de fissuras especifica os termos segundo sua atividade, podendo ser nomeadas ativas ou passivas (THOMAZ, 1989). Como o próprio nome sugere, fissuras ativas encontram-se em atividade, ou seja, têm sua espessura alterada em função da deformação de estruturas. As fissuras passivas são estáveis e não apresentam variação em sua espessura ou comprimento.

A ocorrência de fissuras e trincas tem como fator influenciador a movimentação e consequente deformação da estrutura, que pode ser ocasionada por fatores como a retração do concreto, sobrecargas na estrutura, corrosão da armadura e ainda pelo recalque diferencial da fundação sob a qual está apoiada.

A presença deste tipo de manifestação favorece a abertura da mesma para agentes agressivos, o que dependendo de sua localização poderá ocasionar mais tarde em problemas relacionados às condições de durabilidade e estabilidade da estrutura.

\subsection{Desempenho e Vida Útil das Estruturas}

A vida útil de uma determinada estrutura, seja ela de projeto ou serviço, pode ser avaliada baseando-se na norma NBR 15575 (ABNT, 2013), que estabelece critérios e condições para que os quesitos conforto e qualidade dos sistemas das edificações sejam atendidos.

Considera-se vida útil de projeto o período compreendido entre o início da utilização da estrutura até o momento de despassivação da armadura, em que a frente de carbonatação ou íons cloreto tenham atingido a mesma. É possível estimar o tempo de vida útil de uma determinada estrutura a partir de experiências anteriores, ensaios acelerados, com enfoque determinista ou enfoque estocástico ou probabilista.

Conforme recomendações contidas na norma NBR 15575 (ABNT, 2013), manutenções de caráter preventivo ou corretivo, a depender da demanda apresentada, devem ser planejadas e executadas para que a Vida Útil de Projeto (VUP) seja alcançada, mantendo-se assim as condições de desempenho da edificação.

De acordo com a norma NBR 6118 (ABNT, 2014), o desempenho em serviço incide na "capacidade da estrutura manter-se em condições plenas de utilização durante sua vida útil, não podendo apresentar danos que comprometam em parte ou totalmente o uso para o qual foi projetada". A norma NBR 6118 (ABNT, 2014) estabelece ainda critérios relacionados à durabilidade de estruturas de concreto, sendo definida como a capacidade de uma determinada estrutura resistir às interferências do meio conforme definições de projeto.

Segundo Grandiski (1995), citado por Vidal (2012), "o desempenho das edificações costuma diminuir ao longo do tempo, havendo necessidade de manutenções periódicas até se alcançar o nível de desempenho satisfatório, obrigando geralmente a custosas manutenções e restaurações". Dessa forma, faz-se necessário avaliar os requisitos de projeto em termos de estabilidade e durabilidade, definindo quais defeitos ou manifestações são toleráveis e sua interferência no meio, se representam apenas danos estéticos ou ocasionam em comprometimentos funcional e estrutural.

\subsection{Fundações}

Fundações são elementos estruturais associados ao maciço de solo de fundamental importância para o processo construtivo. São estas as responsáveis por transmitir cargas para a camada resistente do solo, reunindo características capazes até mesmo de inviabilizar a execução de um determinado empreendimento. Durante as etapas de projeto, investigar e conhecer o terreno permitirá a definição do tipo de carga pelas quais o terreno será solicitado, e a maneira como isso se dará, sejam estas cargas variáveis, permanentes ou excepcionais. 
Falhas no desempenho da fundação de edificações poderão ocasionar em adversidades que poderão apresentar-se na forma de pequenas fissuras em argamassas e alvenarias ou até mesmo em situações mais críticas, como o colapso parcial ou total da obra (VIDAL, 2012). Estabelecer limites e projetar fundações para que os valores destes deslocamentos não ultrapassem o valor máximo definido são práticas que garantirão um bom desempenho da estrutura, atuando para que colapsos devido ao surgimento de esforços não previstos em fase de projeto sejam evitados.

As manifestações patológicas verificadas em fundações podem ter sua origem no processo de investigação do subsolo, no projeto e detalhamento, na execução da fundação ou na etapa posterior à conclusão da obra. De acordo com Thomaz (2001), as principais manifestações patológicas associadas às fundações observadas são:

- Insuficiência de levantamentos, sondagens e ensaios;

- Recalques em fundações diretas apoiadas sobre aterros mal compactados;

- Incorreções nos levantamentos geotécnicos;

- Recalques em fundações com estacas e presença de terra solta ou lama;

- Recalques em função do desconfinamento de solos;

- Recalques devido à infiltração de água às fundações;

- Instabilização de taludes por falta de compactação ou proteção;

- Ruptura da fundação constituída por estaca mista;

- Ruptura de fundação por flambagem de estaca tipo Strauss; e

- Ruptura ou recalque em fundações constituídas por estacas cravadas.

A Figura 2 demonstra a forma em que se a manifestação patológica se apresenta em situações em que o subsolo de edificações vizinhas é escavado, ou seja, a partir do processo de desconfinamento do solo.
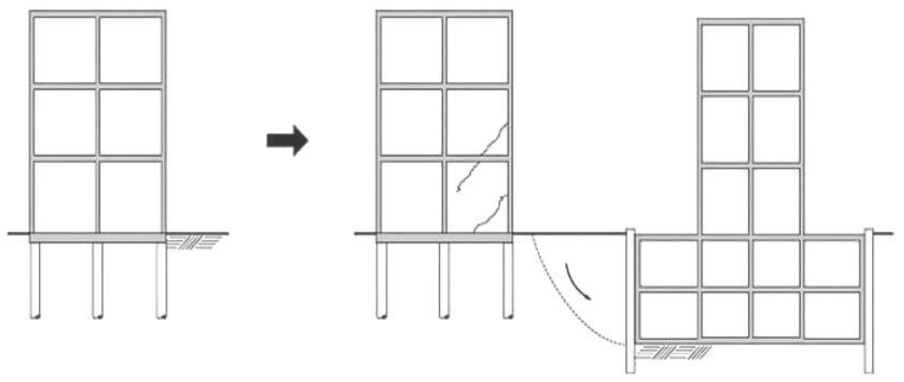

Figura 2: Recalques em função do desconfinamento do solo (THOMAZ, 2001).

A existência de dois ou mais bulbos de tensões diferentes em uma mesma região do solo representa outra possibilidade de manifestação patológica a partir da geração de fissuras na construção. A maneira como as trincas e fissuras se apresentam a partir do recalque da estrutura em casos onde há heterogeneidade no aterro pode ser verificada a partir da Figura 3.

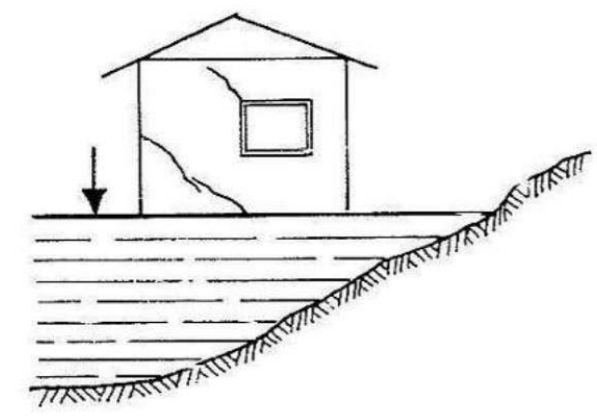

Figura 3: Aterro com espessura variável, assentamento não uniforme (THOMAZ, 1989).

Milititsky (2015) demonstra a correlação entre os deslocamentos nas fundações e o surgimento de fissuras e trincas nas edificações. A Figura 4 apresenta as manifestações patológicas típicas para esta situação: 

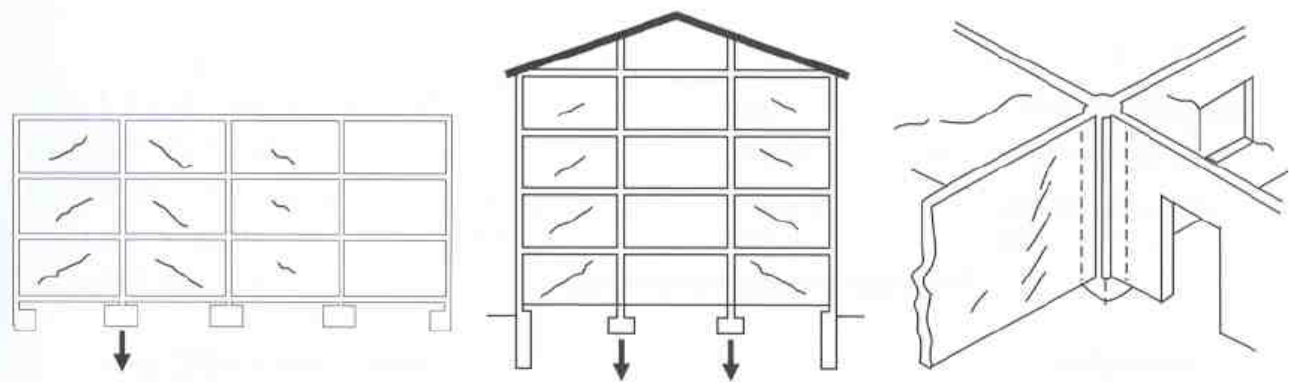

Figura 4: Deslocamento de fundações e a ocorrência de trincas e fissuras (THOMAZ, 2001).

Dentre as patologias associadas às falhas no desempenho das fundações, nota-se a reincidência de trincas com angulação aproximada de $45^{\circ}$ ocasionadas a partir da movimentação das estruturas.

\section{METODOLOGIA}

O presente estudo foi desenvolvido a partir da revisão bibliográfica sobre o tema abordado com análise qualitativa dos dados coletados por meio de métodos não destrutivos como a inspeção visual, anamnese e registros fotográficos. $O$ estudo de caso contemplou a análise dos elementos e inspeção do local por meio de visita técnica, visando definir características como tipo de estrutura e fundação da estrutura, material utilizado e tempo de construção.

\section{ESTUDO DE CASO}

Trata-se de uma edificação construída há aproximadamente 20 anos em alvenaria, localizada em uma cidade do interior de Minas Gerais. A edificação é destinada a uma oficina para manutenção tanto de veículos leves, como também veículos pesados pertencentes ao Poder Público da região. O uso da estrutura sempre esteve associado às atividades como Oficina Mecânica e conta diariamente com algo em torno de 10 funcionários que trabalham diretamente no local, além de receber ainda colaboradores de outros setores e visitantes, por se tratar de um complexo que reúne diversas Secretarias do município.

As visitas técnicas na edificação ocorreram inicialmente entre os meses de Junho e Julho de 2019, contemplando inspeções nas seguintes instalações da edificação: oficina mecânica; escritório; almoxarifado; e demais dependências próximas ao local. Em Janeiro do ano seguinte, uma nova visita foi realizada ao local, constatando-se que a situação percebida anteriormente permanecia. Através das imagens representadas na Figura 5 é possível perceber que a oficina mecânica se encontra em pleno funcionamento, sem restrição de atividades.
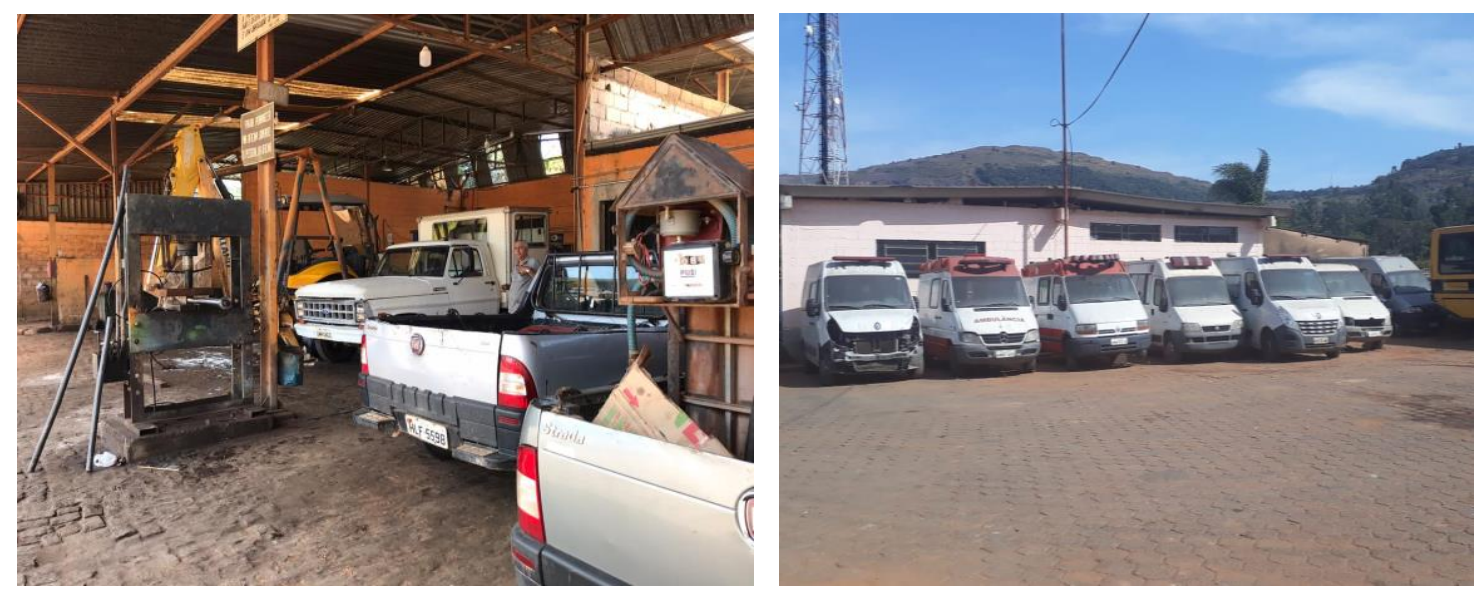

Figura 5: Vista geral do local de estudo, sem restrições de uso (Fonte: Acervo Pessoal) 
Após contato com os servidores locais, constatou-se a inexistência de projeto estrutural para a Oficina Mecânica. De acordo com informações, a edificação foi construída com viga baldrame, uma fundação rasa indicada para pequenas edificações, construída diretamente sobre o solo e sem armadura transversal. Além disso, a obra foi executada sob um aterro de inerte. Não foi possível proceder o levantamento da edificação.

Após a análise foi possível perceber uma maior ocorrência de manifestações patológicas na sala utilizada como escritório pelo pelos funcionários, um cômodo de aproximadamente $30 \mathrm{~m}^{2}$. A sala é utilizada com bastante frequência, local onde ocorrem todas as transações e são definidas as ordens de serviço para execução das atividades.

Por meio da inspeção nota-se uma maior ocorrência de trincas, fissuras e rachaduras na parede frontal (de entrada) do cômodo, sendo possível inclusive observar através dela o lado externo da edificação. As condições em que a mesma foi encontrada são ilustradas nas Figuras 6 e 7.
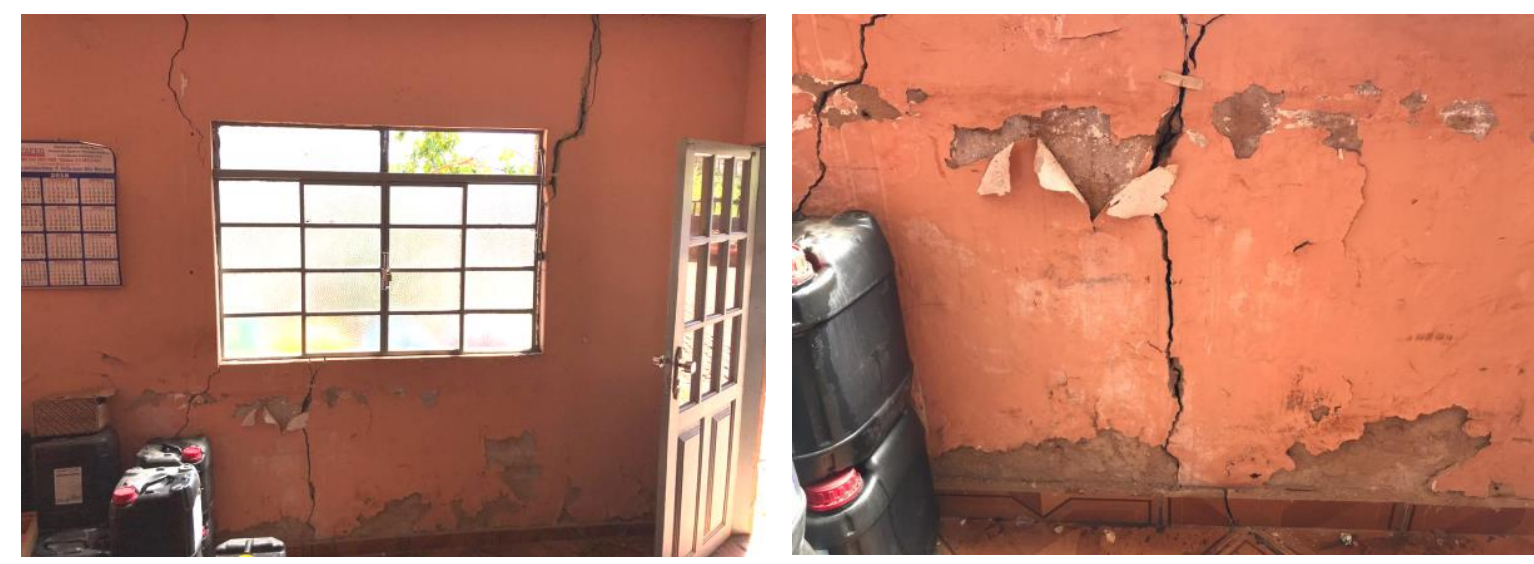

Figura 6: Parede frontal do escritório da Oficina Mecânica, vista de seu interior (Fonte: Acervo Pessoal)

A Figura 7 apresentada a seguir contém imagens que representam períodos distintos de inspeção, sendo a primeira registrada em abril de 2019 e as demais no mês de junho deste mesmo ano e janeiro do ano posterior. A preocupação com a evolução das fissuras, trincas e rachaduras levou funcionários do local a fixarem uma fita adesiva na região das anomalias a fim de observar o comportamento destas.
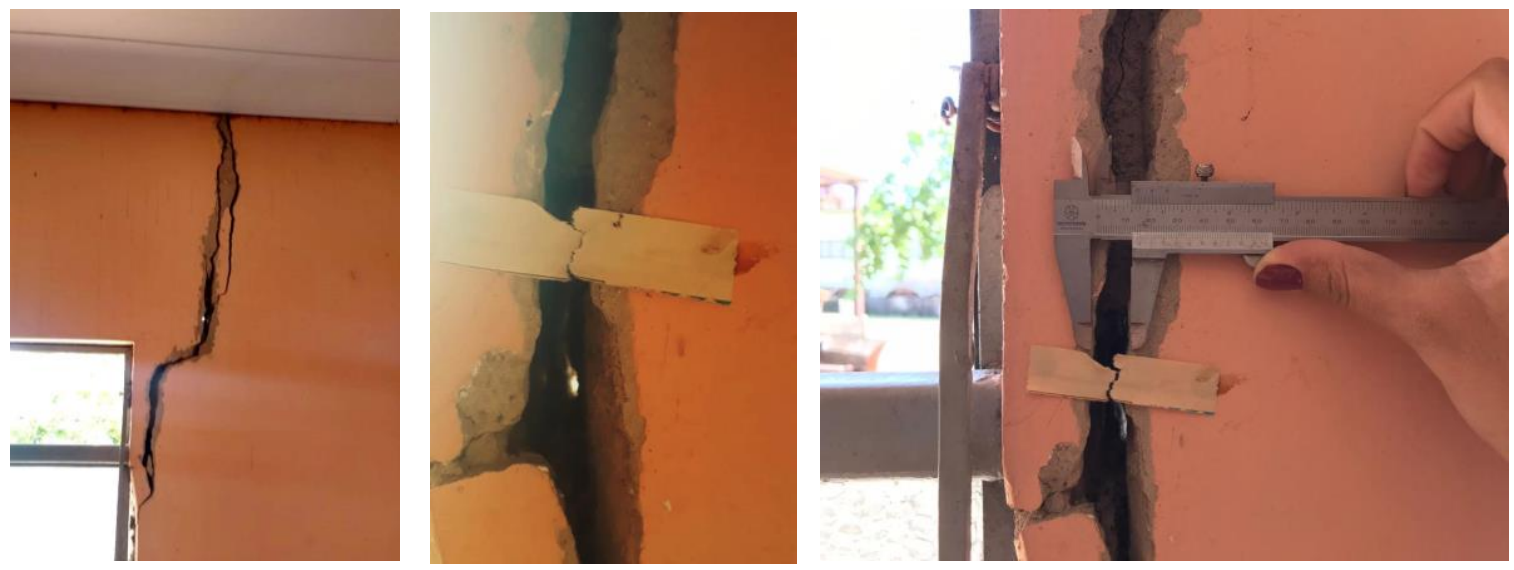

Figura 7: Acompanhamento da evolução das anomalias no escritório da oficina (Fonte: Acervo Pessoal)

A observação por meio de fitas adesivas afixadas no local sinaliza que as manifestações patológicas se encontram em processo de evolução. Nota-se a partir das observações feitas no local que a evolução da anomalia do status de fissura para rachadura ocasionou ainda, em muitas seções, desagregação do concreto, conforme verificado na Figura 8. 

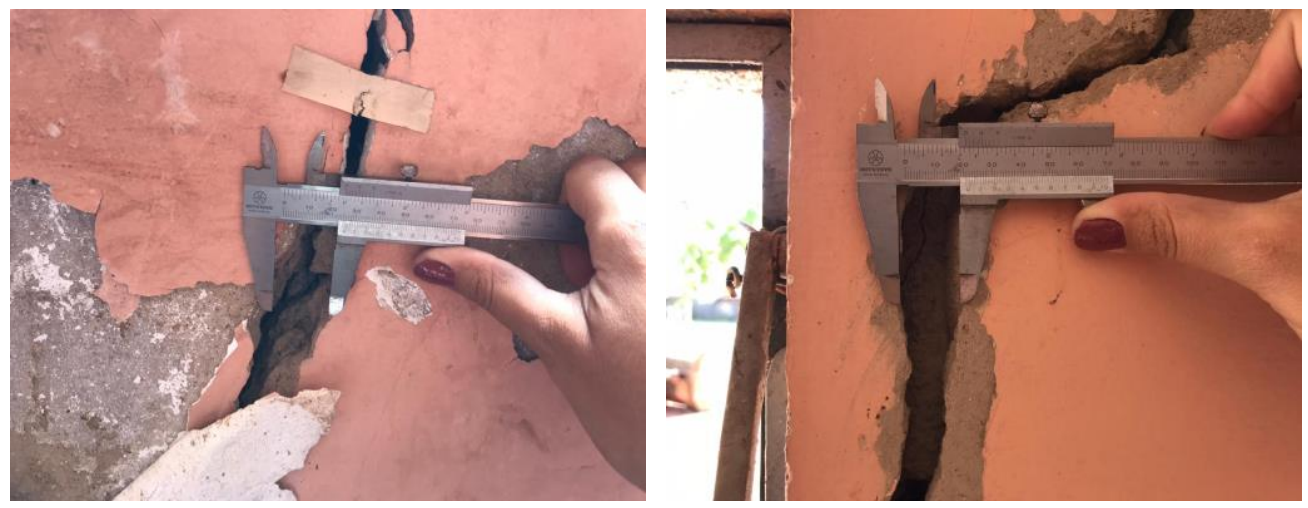

Figura 8: Rachaduras com desagregação de materiais (Fonte: Acervo Pessoal)

De maneira perpendicular ao pilar é possível notar uma trinca que se estende na direção vertical da parede quase em sua totalidade. A anomalia pode ser visualizada a partir do registro representado pela Figura 9.

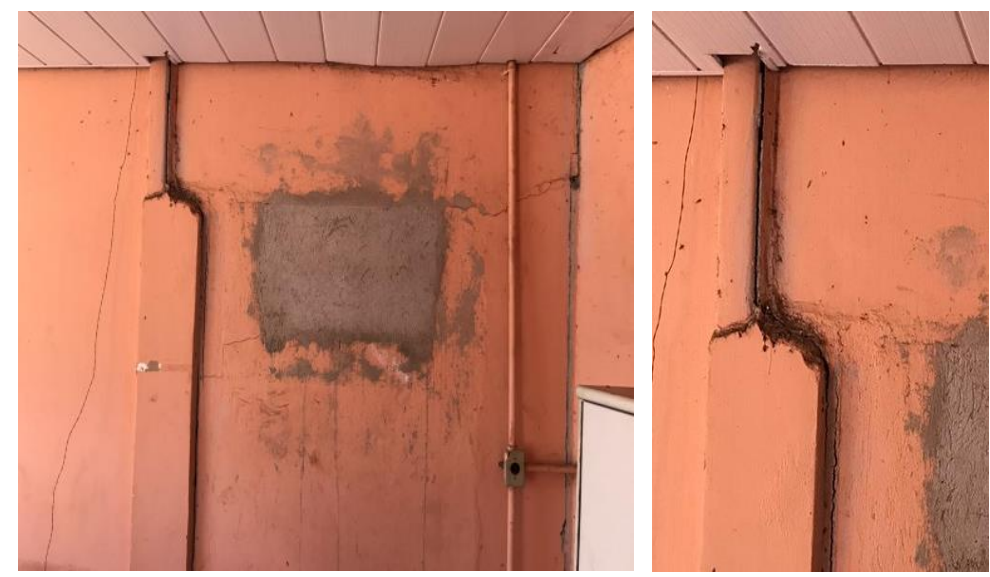

Figura 9: Trinca perpendicular ao pilar (Fonte: Acervo Pessoal)

Apesar da estrutura local não apresentar amarração entre a alvenaria e o pilar, a movimentação do terreno possivelmente é o fator principal e responsável pelo surgimento das trincas. O local utilizado como escritório apresenta ainda patologias no piso, com a abertura das juntas da cerâmica, conforme visualizado na Figura 10. Em algumas regiões é possível perceber a olho nu o rebaixamento de aproximadamente $3 \mathrm{~mm}$ em relação ao nível do piso cerâmico instalado.
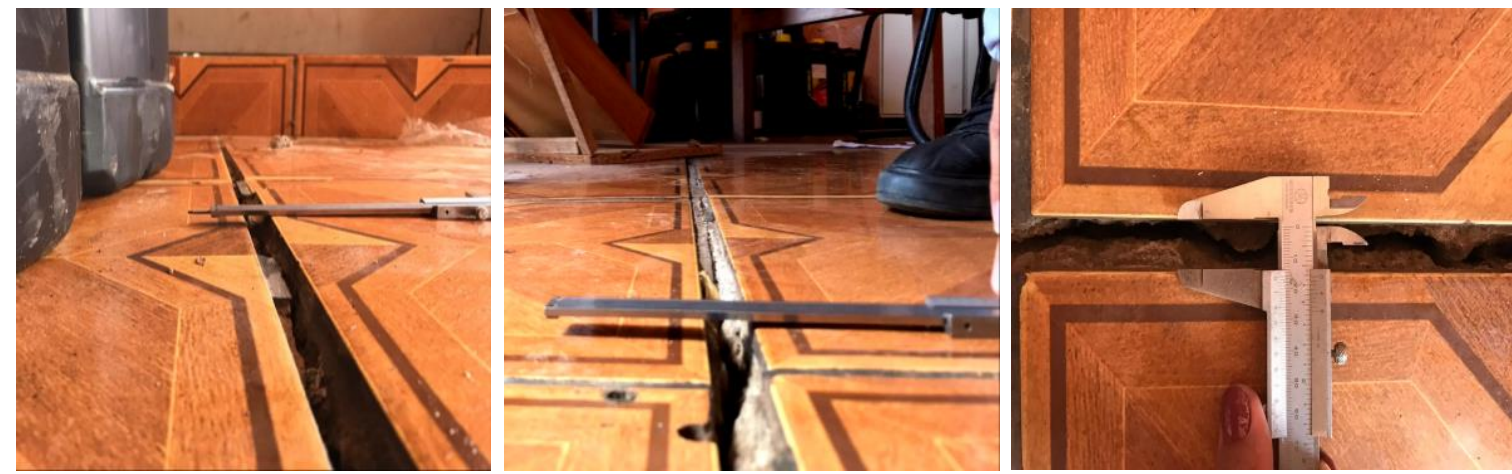

Figura 10: Abertura da junta e rebaixamento do nível do solo (Fonte: Acervo Pessoal)

Trincas e fissuras também podem ser observadas no pátio da oficina, em que o serviço é propriamente executado e onde ocorrem emissões diárias de gases nocivos ao ambiente e estruturas, a partir do sistema de exaustão dos veículos. As trincas podem ser observadas através da Figura 11. 

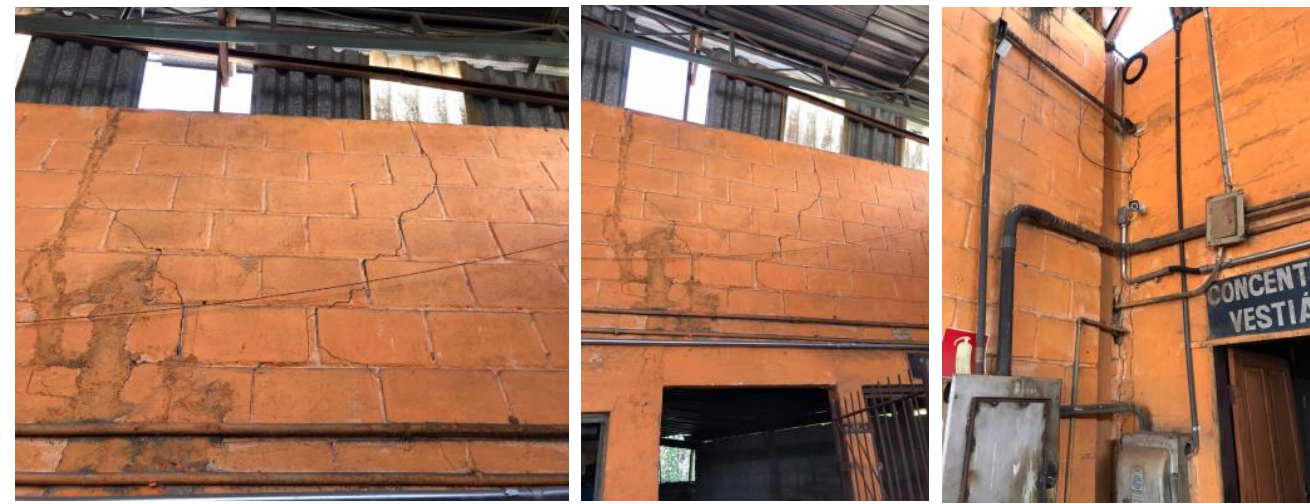

Figura 11: Aberturas com geometrias diversas no interior da edificação (Fonte: Acervo Pessoal)

Rachaduras também podem ser observadas no cômodo localizado ao lado do escritório da Oficina Mecânica (Figura 12), onde grande parte do material utilizado pelos funcionários do local é armazenado, o que promove a circulação no local. Vale ressaltar que as manifestações patológicas presentes na estrutura da parede comprometem a estabilidade do telhado, anomalias notadas não só neste ambiente.
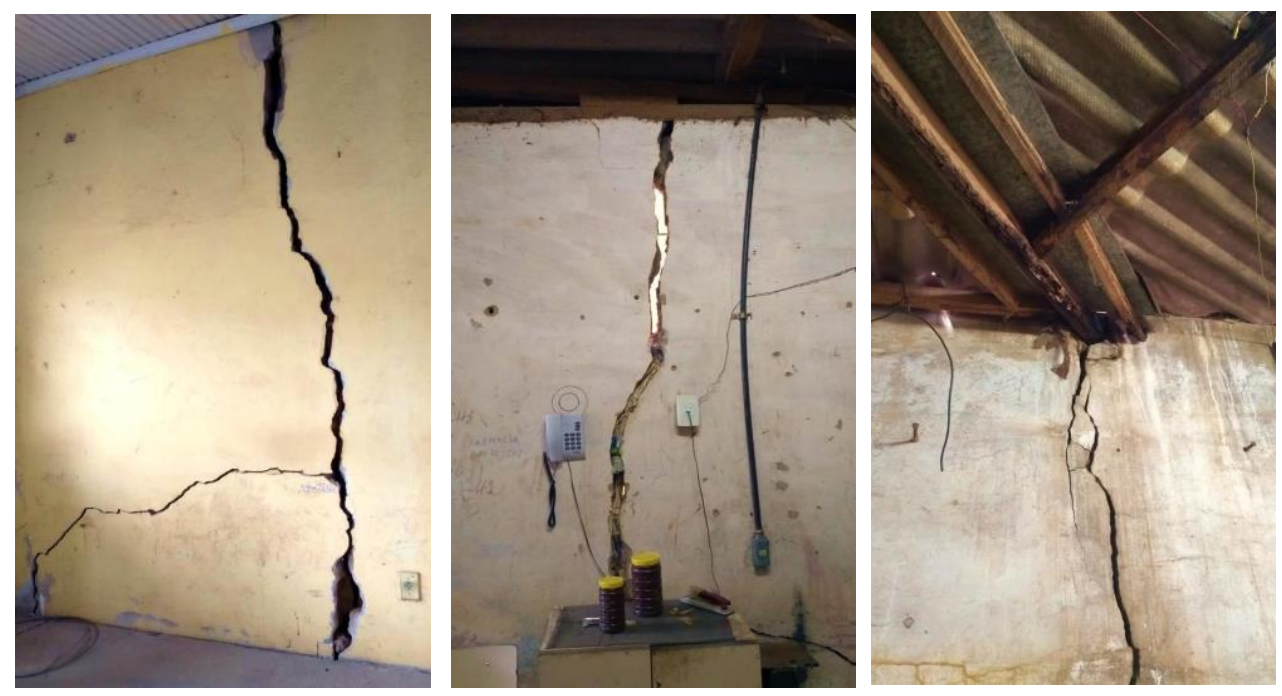

Figura 12: Sala de armazenamento de materiais: trincas e rachaduras na alvenaria (Fonte: Acervo Pessoal)

Ressalta-se que não existem cintas de amarração sobre a alvenaria ou pilarete para descarregar a carga. Contudo, para que se definisse o cenário atual, a movimentação do terreno, associada à inexistência desse elemento estrutural, foi fator determinantes para que tais manifestações surgissem ao longo do tempo. Por inspeção visual foi possível perceber que as trincas e fissuras estavam em processo de evolução, tanto em quantidade, quanto em grau de abertura.

Os funcionários indicados pelo superintendente da repartição para que acompanhassem a vistoria não souberam precisar a data em que as primeiras manifestações patológicas começaram a ser percebidas no local. Contudo, alertaram para o fato de que nenhuma providência foi tomada em relação a isto até o presente momento.

\section{RESULTADOS}

Conforme observado, a grande maioria das manifestações patológicas detectadas está relacionada ao surgimento de fissuras, trincas e rachaduras. É notável a presença de uma quantidade considerável de anomalias com maior grau de 
abertura.A forma de apresentação de parte das trincas e rachaduras em um ângulo aproximado de $45^{\circ}$ aponta para a existência de um recalque diferencial na fundação da edificação construída no local.

O indício de movimentação na fundação, levando em consideração a configuração das manifestações patológicas mais visíveis em uma angulação de $45^{\circ}$, é reforçado pela abertura das juntas no piso e desnivelamento do mesmo. Em conformidade com Thomaz (2001) e Milititsky (2015), a forma geométrica apresentada pelas rachaduras em conjunto com o afundamento do solo indica como possibilidade de diagnóstico a movimentação da fundação e posterior recalque diferencial como agentes causadores.

A construção da edificação sob aterro, a circulação de veículos pesados na localidade e a adoção da viga baldrame como elemento de fundação da edificação, foram fatores associados que possivelmente geraram as manifestações patológicas. A viga baldrame é um tipo de fundação indicada para solos firmes, condição não presente no terreno onde foi assentada a edificação.

\section{DISCUSSÃO}

Em alguns casos, a forma de tratamento indicada para a manifestação patológica em questão engloba a convivência com os danos até que ocorra a estabilização natural da estrutura em análise. Em outros, faz-se necessário o reforço localizado ou reforço generalizado da edificação. O diagnóstico e proposta de intervenção deve sempre considerar se os danos causados apresentam-se a níveis somente estéticos ou se oferecem algum comprometimento funcional ou estrutural para a estrutura.

Embora toda fundação apresente movimentos, o levantamento histórico do problema associado à análise de todas as atividades realizadas durante o processo produtivo indicam o recalque diferencial e posterior movimentação da fundação como agente causador das interferências apresentadas. A estrutura não foi capaz de absorver as cargas solicitadas, comprometendo a estabilidade da edificação.

Apesar de não ser o método de avaliação normatizado, a fixação de fita adesiva em rachaduras da edificação feita por funcionários do local possibilitaram, de alguma forma, o monitoramento das mesmas. Nota-se que as anomalias encontram-se ativas, o que certamente ocasionará no agravamento do cenário. O quadro mais crítico é observado justamente nos cômodos em que ocorre a maior circulação de pessoas diariamente, escritório e sala de armazenamento de materiais, onde a presença de rachaduras é predominante, o que intensifica a preocupação com o caso.

É fato a necessidade de recuperação da estrutura caso as atividades da oficina se mantenham no local, para que sejam garantidas condições de conforto e segurança para os colaboradores tendo em vista o grau de criticidade. Contudo, a existência de uma quantidade de anomalias espalhadas pela área de estudo faz com que seja necessária uma avaliação prévia a fim de verificar o custo final das intervenções e se de fato é viável.

A concepção da edificação sem projeto estrutural é possivelmente um fator que contribuiu para o agravamento das manifestações patológicas. De maneira geral, podemos observar que as manifestações percebidas são típicas de inadequações na fundação e com dimensões que vão desde o surgimento de trincas e fissuras, até a ocorrência de rachaduras. A falta de preparo do terreno para receber esta edificação pode ser considerada como fator inicial, e que desencadeou o surgimento de grande parte das patologias observadas.

Os efeitos decorrentesdas manifestações causaram danos estruturais, arquitetônicos e funcionais, o que ressalta a importância das etapas de projeto e preparo do solo, que devem ser sempre consideradas. Uma possível solução seria promover o reforço da fundação da estrutura, e até mesmo restringir o uso local. Contudo, uma proposta de recuperação de fato deverá contemplar, primeiramente, um processo de investigação do solo.

\section{CONSIDERAÇÕES FINAIS}

As principais manifestações patológicas identificadas na edificação foram fissuras, trincas e rachaduras, presentes em diversas partes do edifício, com incidências relevantes nas paredes e pisos. De uma maneira geral, a configuração das fissuras, trincas e rachaduras permitem atribuí-las a problemas de solo e fundações, o que enfatiza a importância da etapa de projeto como uma forma de minimização de patologias. 
As fissuras, trincas e rachaduras contribuem para a redução da estanqueidade original da edificação, tornando-a mais vulnerável às infiltrações e à manifestação de novas patologias, chegando, inclusive, a comprometer seu uso e vida útil. As manifestações patológicas influenciam na qualidade dos serviços públicos realizados no local, ocasionando constrangimentos psicológicos sobre os usuários.

A realização de inspeções periódicas, como procedimento complementar aos dados obtidos nesse trabalho, auxiliará a equipe técnica do órgão público na quantificação dos danos (evolução no tempo). As manifestações patológicas levantadas estão relacionadas a não adoção de procedimentos mais rigorosos na execução de serviços e na falta de aferição da qualidade dos materiais utilizados na construção da edificação.

Diante do exposto, recomenda-se a mudança do uso atual e monitoramento contínuo da evolução das anomalias na edificação até que a devida recuperação estrutural seja executada, tendo em vista que as atividades realizadas no local atualmente contribuem para a intensificação das manifestações patológicas observadas.

\section{REFERÊNCIAS}

ASSOCIAÇÃO BRASILEIRA DE NORMAS TÉCNICAS. NBR 6118: Projeto de estruturas de concreto Procedimento. Rio de Janeiro, 2014.

NBR 15575: Edificações Habitacionais - Desempenho. Rio de Janeiro, 2013.

HELENE, P. R. L. Manual para reparo, reforço e proteção das estruturas de concreto. São Paulo: Pini, 1992.

HIRT, B. F. Manifestações patológicas em obras de escolas públicas estaduais do Paraná. 2014. 48 f. Trabalho de Conclusão de Curso (Especialização em Patologia das Construções) - Universidade Tecnológica Federal do Paraná, Curitiba, 2014.

LAPA, J. S. Patologia, recuperação e reparação das estruturas de concreto armado. 56f. Trabalho de Conclusão de Curso (Especialização em Construção Civil). Universidade Federal de Minas Gerais, Belo Horizonte, 2008.

MILITITSKY, J.; CONSOLO, N. C.; SCHNAID, F. Patologia das fundações. $2^{a}$ edição. São Paulo: Oficina de textos, 2015.

OLIVEIRA, A. M. Fissuras, trincas e rachaduras causadas por recalque diferencial de fundações. $2012.96 \mathrm{f}$. Trabalho de Conclusão de Curso (Especialização em Gestão em Avaliações e Perícias) - Universidade Federal de Minas Gerais, Belo Horizonte, 2012.

SOUZA, V. C. M.; RIPPER, T. Patologia, Recuperação e Reforço da Estrutura de Concreto. São Paulo: Pini, 1998.

TAGUCHI, M. K. Avaliação e Qualificação das Patologias das Alvenarias de Vedação nas Edificações. 2010. 87f. Dissertação (Mestrado em Construção Civil) - Setor de Tecnologia, Universidade Federal do Paraná, Curitiba.

TRIBUNAL DE CONTAS DA UNIÃO. Relatório de Avaliação da Execução de Programas de Governo n65 Integralização de Cotas ao Fundo de Arrendamento Residencial. TCU, 2016. Disponível em: 〈https://auditoria.cgu.gov.br/download/9141.pdf〉. Acesso em: 10 jun. 2019.

THOMAZ, E. Tecnologia, Gerenciamento e Qualidade na Construção. Editora PINI, São Paulo, 2001.

THOMAZ, E. Trincas em Edifícios: Causas, Prevenção e Recuperação. Editora IPT EPUSP PINI, São Paulo, 1989.

VIDAL, E. C. Avaliação de Patologias em Conjuntos Habitacionais de Bauru, com Enfoque em Anomalias de Fundações e de Coberturas. 2012. 125 f. Dissertação (Mestrado em Engenharia Civil) - Faculdade de Engenharia Civil, Arquitetura e Urbanismo, Universidade Federal de Campinas, Campinas. 